\title{
Social Research Methods In Feminist's Perspective: A New Way in Doing Sociolinguistic Qualitative Research
}

\author{
Esther Kuntjara
}

\begin{abstract}
Traditional research methods have been dominated by positivism which assumes the importance of objectivity, contextual independency, linear causality and value free research. Feminist researchers found that such methods do not suit their inquisitive needs especially in the study of women. Naturalistic research methods, however, do not only suit them but they are also able to voice women's problems. Two methods, i.e. interviewing and ethnography are discussed as to how they are commonly used by feminist researchers on many social studies on women, including the linguistic studies of gender.
\end{abstract}

Keywords: positivism postpositivism, naturalistic, feminism, ethnography, interview, qualitative.

\section{Introduction}

Traditional methods in social studies have been dominated by positivism. In the prepositivist era, researchers were influenced by Aristotle's principles, commonly known as the Law of Contradiction, which states that no proposition can be both true and false at the same time; and the Law of the Excluded Middle, which holds that every proposition must be either true or false. Using these principles, researchers are noninterventionists or passive observers.

When scientists began to reach out and touch to try ideas and see if they worked, they became active observers. Then science passed into the positivist period. Positivism, according to Reese (1980), can be defined as "a family of philosophies characterized by an extremely positive evaluation of science and scientific method" (p.450). In fact, different scientists and philosophers had somewhat different views of what positivism implied and on what ground it stood. Hence, positivism can be reshaped to suit the definer's purpose. In short, however, positivism rests on at least five assumptions (Lincoln \& Guba, 1985, p. 28):

1. An ontological assumption of a single, tangible reality "out there" that can be broken apart into pieces capable of being studied independently; the whole is simply the sum of the parts.

2. An epistemological assumption about the possibility of separation of the observer from the observed - the knower from the known.

3. An assumption of the temporal and contextual independence of observations, so that what is true at one time and place may, under appropriate circumstances (such as sampling) also be true at another time and place. 
4. An assumption of linear causality; there are no effects without causes and no causes without effects.

5. An axiological assumption of value freedom, that is, that the methodology guarantees that the results of an inquiry are essentially free from the influence of any value system (bias).

Many sociolinguistic research methods in the 60ies and 70ies were dominated by postivism known as the Labovian quantitative sociolinguistics (Cameron, 1997). Cameron further noted that in order to understand people's linguistic behavior and attitude, the linguistic system must at some level be brought about by the actual speakers, which is an approach to language in society which cannot be addressed within the assumptions of the quantitative paradigm. Critiques directed to positivism led to an extreme degree of discomfort among practicing scientists. The next era then emerged and it was called postpostivism. The basic tanets of postpositivism are virtually the reverse of those that characterized positivism. They basically constitute a reaction to the failings of positivism. Habermas (in Lincoln and Guba, 1985) proposed five counterpoints which have now come to characterized the natural sciences as well. Lincoln and Guba themselves term postpositivist paradigm as the "naturalistic paradigm." Apparently the paradigm in postpositivism seems to suit the more current development in sociolinguistic studies as well.

The axioms of the naturalistic paradigm are as follows:

1. There are multiple constructed realities that can be studied only holistically; inquiry into these multiple realities will inevitably diverge so that prediction and control are unlikely outcomes although some level of understanding can be achieved.

2. The inquirer and the 'object' of inquiry interact to influence one another; the knower and the known are inseparable.

3. The aim of inquiry is to develop an idiographic body of knowledge in the form of "working hypotheses" that describe the individual case.

4. All entities are in a state of mutual simultaneous shaping so that it is impossible to distinguish causes from effects.

5. Inquiry is value-bound. It is influenced by inquirer values, the choice of the paradigm that guides in the investigation into the problem, the choice of the substantive theory, the values that inhere in the context. Inquiry must exhibit value-resonance if the inquiry is to produce meaningful results.

\section{Feminist's Perspective in The Naturalistic Paradigm}

Looking at the naturalistic paradigm, many feminist researchers found that the application of the paradigm in social research does fit both female researchers and the study of women. At first they found that many traditional researches which employed the positivist methods reflect male's perspective. Such research which regards objectivity, quantitative method, value free and distancing the researcher from the researched is viewed as very un-feminine. The use of naturalistic research method, on the other hand, values subjectivity, is value-bound, uses more flexibility such as in the use of qualitative method, while sees and values the researcher and the subject being researched as a holistic entity which is mutually influencing. Hence, for feminist 
researchers, naturalistic methods have developed sense of connectedness with people and more egalitarian research methods (Reinharz, 1992, pp. 20-21).

Feminist sociolinguists also find naturalistic methods appropriate for the studies of language, for they see that numerical summaries obscure the subtleties of meaning that language is designed to convey. These methods that are used in sociolinguistic research treat linguistic values and social values as equivalent. Sociolinguistics need research methods, which can uncover the social meanings that attach to linguistic categories, and how language shapes our social worlds. What we need to study is the processes of linguistic construction rather than their products. In doing naturalistic research there are several commonly used methods that suit many feminist researchers. Among others that will be discussed here are interviewing and ethnography.

\section{Interviewing}

One model of naturalistic interviewing, according to Rubin and Rubin (1995), is to emphasize the relativism of culture, the interviewer's active participation, and the importance of giving the interviewee's voice (p.31). By emphasizing the relativism of the culture the interviewer will try to learn from the interviewee and see from his/her point of view. He/she will not impose his/her own norms and values on the situation. Active participation does not mean the interviewer's domination in the interaction, but rather he/she will allow the interviewee to express himself/herself more. The goal of qualitative interview is more than just obtaining surface data. It should also try to understand specific circumstances, including how and why things actually happen.

Researchers who use the naturalistic method should admit that interviewing includes the emotional involvement of the interviewer. The interview may be affected by the interviewer's moods, interests, biases, experiences, and personality. It is impossible for a naturalistic research to remain value free or neutral. He/she might try to impress the interviewee with his/her opinions and assumptions. However, it would be advisable that the interviewer follow the moods of the interviewee (Rubin and Rubin, 1995). The results of such interviews can be very interesting and have often been said to provide excellent material. Hence, naturalistic interviewing is a way of learning about people's feelings, thoughts, and experiences. It will also allow the interviewee to explore the questions in depth.

Some feminist researchers make some suggestions concerning interviewing that is especially evident with women interviewees. They have developed a model of how to ask questions. Feminist discourse analysis has made scholars aware of both the surface and the deeper reflexive structures of rhetoric. They have stressed the importance of ensuring that the methods we use fit the different experiences of women. They argue that the questions should allow the interviewee to voice her experience in her response openly. Interviews that are carried out with women should be more open and loosely structured. It should resemble normal conversation. The interviewer and the interviewee need to collaborate and produce an interview that will help the interviewee rather than using her for the purpose of the researcher. During the process of such an interview the researcher needs to be aware of issues that are personal and private. In this case the researcher will have to develop trustworthiness so that women informants will be more open and relaxed. Using a setting where women may feel most relaxed when interviewed will allow them to find themselves (Warren, 1988; Olsen, 1994; Bird, 1995). 
Building trustful relationship needs time. However, faminist researchers admit that the element of subjectivity in the research enables them to understand more about women's problems. They believe that the results they get from such research have opened a new way for scientists to see the world differently. It has been a new experience, which was by far neglected in the traditional positivist research.

In sociolinguistic research, the use of naturalistic interviewing will be able to present an in depth study of how and why a particular speech act is carried out by a particular speaker. Instead of making a generalized statement based on the answers given in a questionnaire, the researcher can probe on the answers through interviewing and looking at all possible context in trying to account on the validity of the answers.

\section{Ethnography}

Contemporary ethnography is a multimethod research. It usually includes observation, participation, archival analysis, and interviewing. It relies on researcher's immersion in social settings, and aim for intersubjective understanding between researchers and the person(s) studied. Reinharz (1992) wrote:

Some feminist researchers continue to reject positivism as an aspect of patriarchal thinking that separates the scientist from the phenomenon under study. They repudiate the idea of a social reality "out there" independent of the observer. Rather, they think that social research should be guided by a constructivist framework in which researchers acknowledge that they interprete and define reality. In this context, feminist fieldwork has a special role in upholding a nonpositivist perspective, rebuilding the social sciences and producing new concepts concerning women (p. 46).

The challenge for feminist ethnographers is to use the fieldwork to get closer to women's realities. Just like naturalistic interviewing which can make women's voice audible, feminist method in ethnography can make women's lives visible. It is consistent with three goals: First, to document the lives and activities of women; second, to understand the experience of women from their own point of view, and third, to conceptualize women's behavior as an expression of social contexts (Reinharz, 1992, p. 51).

Many feminist ethnographers believe that women's interest in feelings made them better ethnographers. Women are used to establishing relationships, learning to see, think and be in another culture. Women's distinctive social experience, including that of gender domination, makes them sensitive to the domination of others.

Feminist ethnographers also found that they can get more freedom in formating the results of their research. While the traditional positivist methods often use quantitative numbers and statistics in the research report, feminist ethnographers often present their report in a narrative form. It may look like a biography or a memoir of the person(s)'s life experience and it also reflects the life of the researcher. Bell et.al. (1993) maintained that "women's experimental texts, with their preference for autobiography, biography and dialogue, are a manisfestation of their search for a mode of presentation that represents their experience as affective and their knowledge as grounded in specific relations (pp. 6-7). Feminist researchers believe that it is the human interaction or relation, which is the heart of the research, which suits women's experience.

Many current linguistic researches found ethnography an interesting method of investigating a case study, especially one which has something to do with the problems 
of women. By immersing into the setting and probing into the real life of the subject being researched, a researcher will be able to see the context which can provide great power for understanding and making predictions about social settings that influence their language use. In using this method, the linguistic researcher will spend many hours with the subject to find out the gentle nuances of her speech by eating, working and playing with her. Hence, the data the researcher finds will present in depth understanding of the case.

There is no single best method of collecting information on the patterns of language use within a speech community. Appropriate procedures depend on the relationship of the researcher as the ethnographer and the speaker or the speech community and the particular situation in which fieldwork is conducted. Collecting data in situations in which the researcher him/herself is taking part requires the ethnographer to include data on their own behaviors in relation to others, and an analysis of his/her role in the interaction as well as those of others (Saville-Troike, 1997).

\section{Conclusion}

Social research methods, which use naturalistic paradigm has been viewed as a new way of answering the challenge of understanding the life of postmodern society. Positivist methods are thought to have failed in providing the real answers to the postmodern life style, which is characterized by its complicated human experience where multiple realities are contingent. Language is far too active, creative and influential a phenomenon to be studied within a positivist tradition.

Naturalistic research methods have opened many possibilities for women to voice their problems, which are getting more crucial as world problems. Feminist research has invariably been the source of many new insights and has opened up new and challenging areas for future research. It is not unbiased. Feminists have found it necessary to go beyond the traditional linguistic boundaries. Feminist research has opened up an area in which more and more useful answers can be found.

\section{References}

Bell, D., Caplan, P., \& Karim, W.J. (1993). Gendered fields: Women, men and ethnography. London: Routledge.

Bird, S.E. (1995). Understanding the ethnographic encounter: The need for flexibility in feminist reception studies. Women and language, 18, 2, 22(5).

Cameron, D. (1997). Demythologizing Sociolinguistics. In N. Coupland \& A. Jaworski (Eds.) Sociolinguistics: A reader (pp.55-67). New York: St. Martin's Press.

Lincoln, Y.S. \& Guba, E.G. (1985). Naturalistic inquiry. Newbury Park, London: Sage Publications.

Olesen, V. (1994). Feminism and models of qualitative research. In N.K. Denzin \& Y.S. Lincoln (Eds.) Handbook of qualitative research (pp. 158-171). Thousand oaks: Sage Publications. 
Reese, W.L. (1980). Dictionary of philosophy and religion. Atlantic Highlands, NJ: Humanities.

Reinharz, S. (1992). Feminist methods in social research. New York: Oxford University Press.

Rubin, H.J. \& Rubin, I.S. (1995). Qualitative interviewing: The art of hearing data. Thousand Oaks: Sage Publications.

Saville-Troike, M. (1997). The ethnographic analysis of communicative events. In N. Coupland \& A. Jaworski (Eds.) Sociolinguistics: A reader (pp.126-144). New York: St. Martin's Press

Warren, C.A.B. (1998). Gender issues in field research. Qualitative Research Methods Series 9. Newbury Park: Sage Publications. 